\title{
Blended Learning: Workshop Penggunaan Google Form dan Google Classroom Bagi Guru SMP Negeri 34 Semarang
}

\author{
Agnita Siska Pramasdyahsari ${ }^{1)}$, Sutrisno $^{2)}$, Rina Dwi Setyawati ${ }^{3)}$, \\ Noviana Dini Rahmawati, ${ }^{4)}$, Dhian Endahwuri ${ }^{5}$
}

\author{
Pendidikan Matematika, Fakultas Pendidikan Matematika, Ilmu Pengetahuan Alam dan \\ Teknologi Informasi, Universitas PGRI Semarang, Indonesia ${ }^{1,2), 3), 4), 5)}$ \\ Pos-el: aghrathalita@gmail.com
}

\begin{tabular}{|l|l|l|}
\hline Dikirim: 04, 02, 20 & Direvisi: 24, 02, 2020 & Diterbitkan: 28, 02, 2020 \\
\hline
\end{tabular}

\begin{abstract}
Abstrak
Permasalahan utama yg dialami oleh pihak mitra pengabdian SMP Negeri 34 Semarang adalah (1) belum memiliki sumber daya manusia yang mampu menerapkan blended learning, terutama dengan menggunakan google form dan google classroom; (2) guru belum memanfaatkan teknologi informasi secara optimal; (3) guru belum optimal secara teknis dalam mempublikasikan bahan ajar dan media pembelajaran menggunakan teknologi. Sehingga, untuk meningkatkan kemampuan guru dalam menyediakan media pembelajaran yang lebih menarik dan menyenangkan diberikan workshop blended learning pembuatan google form dan google classroom. Metode pelaksanaan dalam program kemitraan ini adalah ceramah, praktik, tanya jawab dan penugasan. Pelaksanaan program berlangsung selama dua hari dengan rincian workshop hari pertama tentang google form beserta praktik dan penugasan. Selanjutnya, workshop hari kedua tentang google classroom beserta praktik dan penugasan. Adapun hasil dari kegiatan ini adalah peserta workshop mampu membuat akun, merancang bahan ajar dan alat evaluasi dalam bentuk google form dan google classroom. Selain itu, guru lebih optimal secara teknis dalam mempublikasikan bahan ajar dan media pembelajaran menggunakan teknologi.
\end{abstract}

Kata Kunci: Blended learning, Google Form, dan Google Classroom

\begin{abstract}
The main problems of SMP Negeri 34 Semarang are (1) do not have human resources who capable of implementing blended learning, especially by using the google form and google classroom; (2) teachers have not used information technology optimally; (3) the teacher is not yet technically optimal in publishing teaching materials and instructional media using technology. Therefore, to improve the teachers' ability in providing learning media that are more interesting and enjoyable, a blended learning workshop is provided for making google forms and google classroom. The methods in this partnership program are lectures, practices, questions-answers and assignments. The program was occured for two days with details of the first day's workshop on google forms along with their practices and assignments. Meanwhile, the second day's workshop was on google classroom along with practices and assignments. The results of this activity are workshop participants are able to create an account, design teaching materials and evaluation tools through google forms and google classroom. In addition, teachers are more technically optimal in publishing teaching materials and learning media using technology.
\end{abstract}

Keywords:Blended learning, Google Form, and Google Classroom 


\section{PENDAHULUAN}

Perkembangan teknologi perlu disinergikan dalam pembelajaran di era digital. Oleh karena itu, guru sebagai salah satu pilar strategis penopang pelaksanaan dan peningkatan mutu pendidikan menjadi hal yang utama dalam mewujudkan pembelajaran yang asyik dan menumbuhkan motivasi anak untuk belajar. Sejalan dengan Peraturan Pemerintah RI Nomor 74 Tahun 2008 tentang Guru (PP, 2008), dan Peraturan Menteri Pendidikan Nasional Nomor 18 Tahun 2007 tentang Sertifikasi Guru dalam Jabatan (Permen, 2007), membuktikan kuatnya komitmen Pemerintah untuk menghasilkan guru yang berkualitas. Peraturan ini yang seharusnya dapat mendorong guru menjadi inovatif dan kreatif.

Dalam era digital seperti saat ini, hal yang harus dikuasai guru di antaranya adalah menciptakan suasana belajar yang menyenangkan dan menstimulasi siswa agar interaktif dalam pembelajaran. Salah satunaya adalah mempersiapkan bahan ajar berbasis daring sehingga sistem pembelajaran tidak hanya terpaku di ruang kelas. Tersedianya bahan ajar dan media secara online akan mempermudah siswa mengakses sumber belajar melalui bantuan internet dimana pun dan kapanpun. Sejalan dengan Bishop (1989) yang memprediksikan bahwa pendidikan masa mendatang akan bersifat luwes (flexible), terbuka, dan dapat diakses oleh siapapun maka penting agar guru memperbarui keilmuan dan mengikuti perkembangan teknologi serta mengkolaborasi pembelajaran dengan teknologi melalui aktivitas blended learning.

SMP N 34 merupakan salah satu sekolah di Semarang yang berlokasi di jalanTlogomulyo Semarang, mempunyai 37 guru yang tersebar di berbagai matapelajaran dan sekitar 800 siswa. Penerapan Kurikulum 2013 menuntut guru untuk lebih inovatif dan kreatif dalam proses pembelajaran dan bersinergi dengan perkembangan teknologi yang ada. Akan tetapi, ketersediaan bahan ajar berbasis daring masih menjadi kendala bagi guru. Hal ini dikarenakan karena kurangnya workshop dan pelatihan media pembelajaran yang diadakan bagi para guru. Berdasarkan hal tersebut, para guru perlu mengikuti pelatihan blended learning untuk menambah wawasan teknologi yang dapat dimanfaatkan untuk meningkatkan sistem pembelajaran di kelas. Saat ini, pemanfaatan teknologi yang dilakukan oleh guru dalam pembelajaran masih terbatas pada penggunaan powerpoint di kelas.

Berdasarkan analisis situasi tersebut, tim pengabdi ingin melakukan pelatihan blended learning. Beberapa peneliti mendefinsikan blended learning sebagai pengajaran tatap muka langsung dan pengajaran berbasis teknologi (Grgurovic, 2011; Qiu, Chen, 2011; Tucker, 2012). Meskipun demikian Ahrens, Zascerinska, and Andreeva (2013) dalam artikelnya menyebutkan bahwa blended learning tidak hanya fokus pada sinergi pembelajaran konvensional dengan pembelajaran berbasis teknologi akan tetapi juga memperhatikan peningkatan kualitas pembelajaran pada peserta didik.

Dalam kegiatan pengabdian ini, kegiatan blended learning yang diperkenalkan kepada para guru adalah penggunaan google form dan google classroom. Harapan yang diinginkan adalah variasi dan keberagaman media belajar dalam proses belajar mengajar, dan guru mampu mempublikasikan media dan bahan ajar secara konvensional dan berbasis daring dalam penerapan strategi pembelajaran blended learning serta meningkatkan kemampuan guru untuk menyediakan media pembelajaran yang lebih menarik dan menyenangkan dengan menggunakan teknologi. 


\section{METODE}

Program kemitraan ini dilaksanakan di SMP Negeri 34 Semarang selama bulan Oktober 2019 hingga November 2019. Proses kemitraan masyarakat ini terbagi dalam tiga tahapan yaitu persiapan, pelaksanaan dan evaluasi program. Pada tahap persiapan, tim pengabdi melakukan koordinasi dengan pihak sekolah melalui diskusi untuk mengidentifikasi permasalahan yang terjadi di lingkungan sekolah, identifikasi tentang optimalisasi penggunaan teknologi informasi dan mengecek kesiapan ketersediaan fasilitas computer untuk media pelatihan. Selain itu, pada tahap persiapan, tim pengabdi bekerjasama dengan SMP Negeri 34 Semarang untuk menyusun perencanaan pelaksanaan pelatihan yang meliputi penentuan jadwal pelatihan, tempat pelatihan, agenda, tenaga pelatih dan kepanitiaan. Tahap selanjutnya adalah pelaksanaan program kemitraan masyarakat yang dilaksanakan pada tanggal 23 dan 24 November 2019 yang diikuti oleh 33 peserta guru SMP Negeri 34. Pemberian pelatihan, modul dan kebutuhan penunjang pelatihan dilakukan oleh tim pengabdi. Sedangkan, media komputer dan tempat pelatihan disiapkan oleh pihak SMP Negeri 34 Semarang. Metode pelatihan dilakukan melalui praktek, tanya jawab dan pendampingan secara individu. Materi pelatihan disajikan dengan lebih banyak praktek dibandingkan teori, dengan rasio $25 \%$ teori dan $75 \%$ praktek. Sedangkan pada tahap evaluasi, tim pengabdi melakukan evaluasi hasil kerja praktik yaitu produk dilakukan terhadap mitra oleh tim pengabdi. Teknik evaluasi hasil program pelatihan dilakukan dengan penilaian hasil kerja praktik, yaitu produk Google Form dan Google Classroom.

\section{HASIL DAN PEMBAHASAN}

Secara umum, pada kegiatan yang dilaksanaan selama dua hari terlihat bahwa sebagian besar peserta belum menerapkan media dan evaluasi pembelajaran berbasis teknologi dalam proses belajar mengajar. Para guru masih menggunakan cara konvensional dalam kegiatan pembelajaran. Guru-guru juga belum memiliki gambaran tentang media-media pembelajaran yang berbasis teknologi berbasis online atau mobile. Padahal, google form dan google classroom yang diakses secara online mengharuskan setiap pengguna memiliki akun google dan email. Sehingga, sebagian besar peserta terkendala dengan pembuatan akun karena lupa dengan ID dan password email yang sudah pernah dibuat. Selain itu, banyak peserta masih bingung dalam mengikuti langkah-langkah dalam pelatihan meskipun telah melalui pendampingan individu. Beberapa peserta bahkan masih ada yang belum familiar dalam pengoperasian komputer.

Selanjutnya pada hari kedua, sebagian peserta sudah mulai lebih lancar dalam mengikuti pelatihan karena tidak lagi terkendala email dan "lebih berani" dalam mengoperasikan komputer. Namun tersandung kendala lagi ketika sebagian peserta masih belum familiar dengan cara masuk ke akun google form dan google classroom.

Selain praktikum berdasarkan petunjuk dari pembicara, peserta diminta untuk membuat produk tanpa bimbingan langsung dari pemateri. Namun tetap diarahkan oleh tim pengabdian kepada masyarakat. Selanjutnya peserta diminta untuk mengumpulkan hasil produk yang telah dibuat selama pelatihan. 
Berikut disajikan pada Gambar 1 mengenai materi dari modul pelatihan google form dan google classroom yang disampaikan kepada para guru mulai dari pengenalan google classroom dan langkah - langkah pembuatan google classroom.
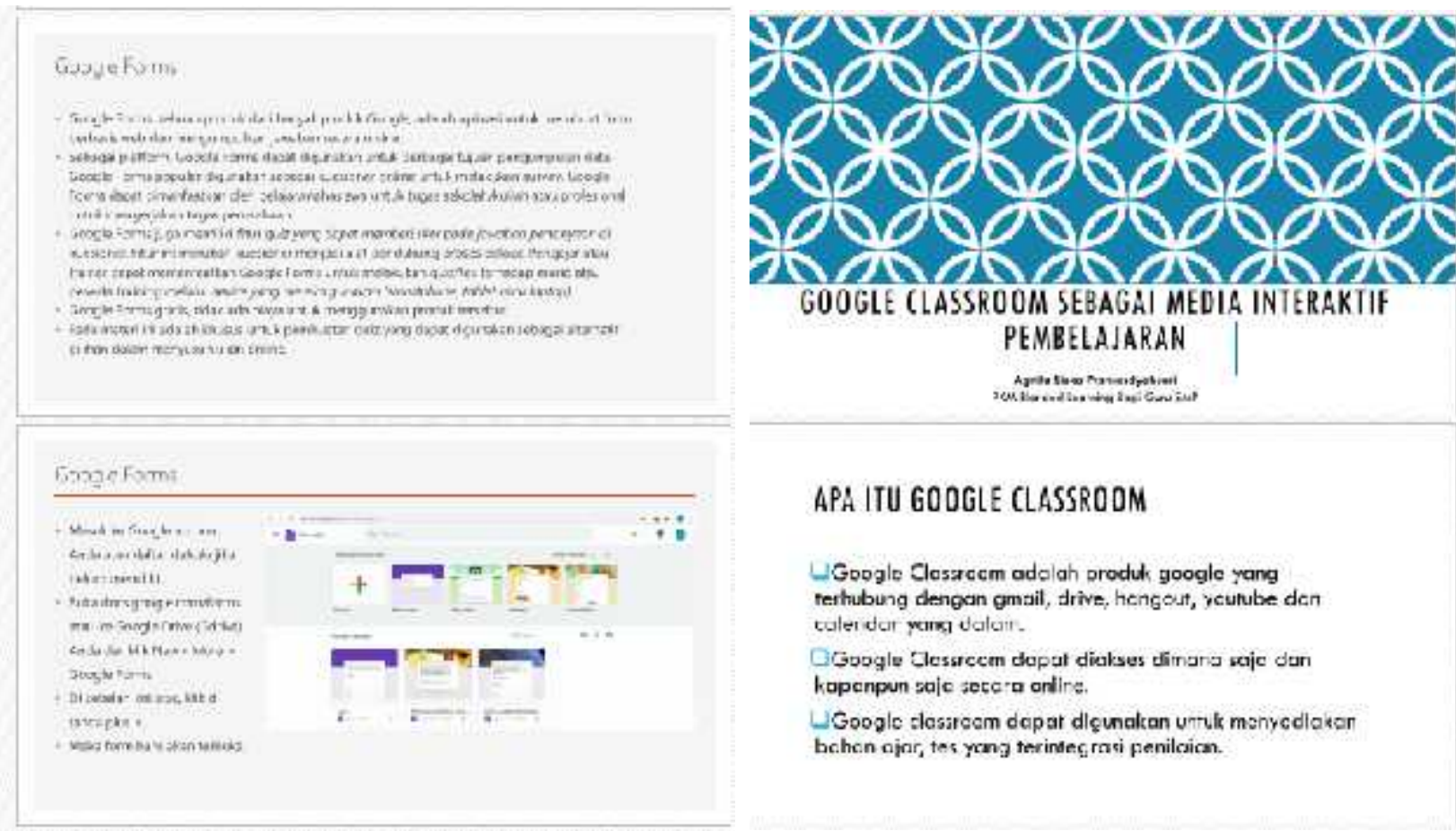

\section{APA ITU GOOGLE CLASSROOM}
LGopgle Clesxcem adolah produk google yang rerhubung dengan gmail, drive, hengest, yeuhube den taler dar park dalar -
GGopgle Clessrecm dapat diakses dimans saje dan kapenpun saje seecra onlire.
Loogle slesarsem dopar dlęunalcan utulk menycdeker bohen ojur, tes yong terindeç raxi penilcaica.

\section{Gambar 1. Modul Pelatihan Google Form dan Google Classroom}

Selanjutnya pada Gambar 2 disajikan salah satu hasil produk pembuatan Google Classroom. Selain melakukan praktik langsung pada saat bersamaan dengan pemateri, peserta kegiatan juga mendapatkan tugas untuk menyusun sendiri google classroom yang dapat dipersiapkan sesuai dengan mata pelajaran yang diampu.

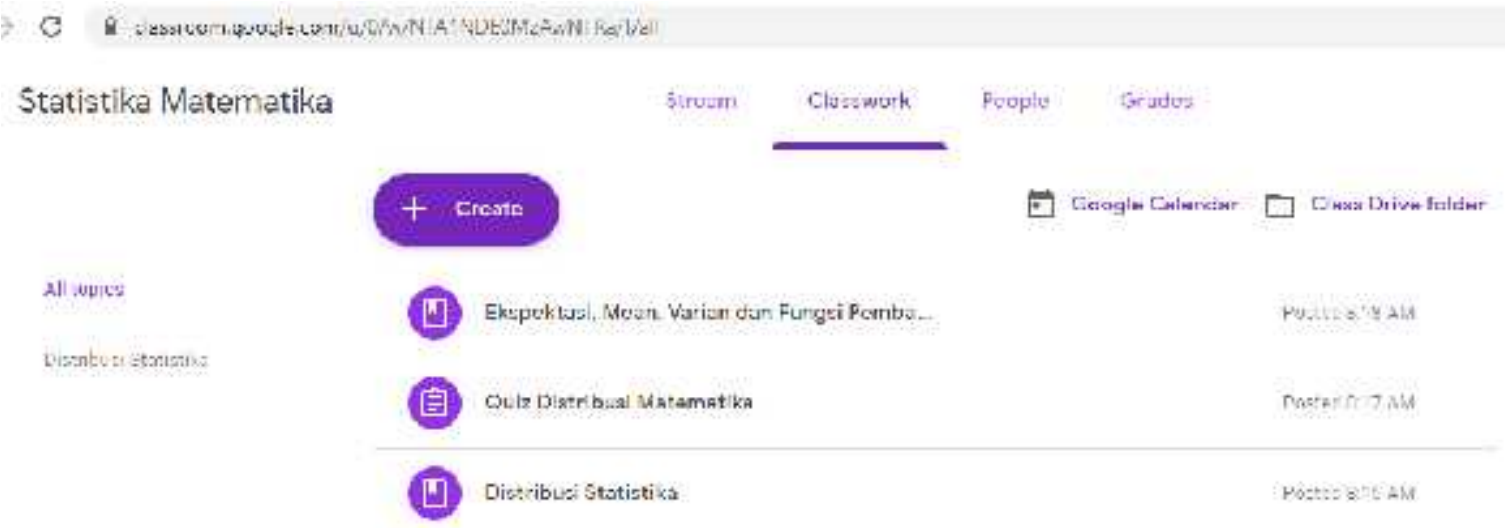

Distribusi Statistika

目 Distrinua statiatika

Gambar 2. Contoh Hasil Kerja Pembuatan Google Classroom 
Peserta kegiatan workshop blended learning pembuatan google form dan google classroom mendapatkan pendambingan dan bimbingan individu pada kegiatan praktik. Sehingga para peserta diharapkan dapat menyusunnya sendiri saat penugasan.
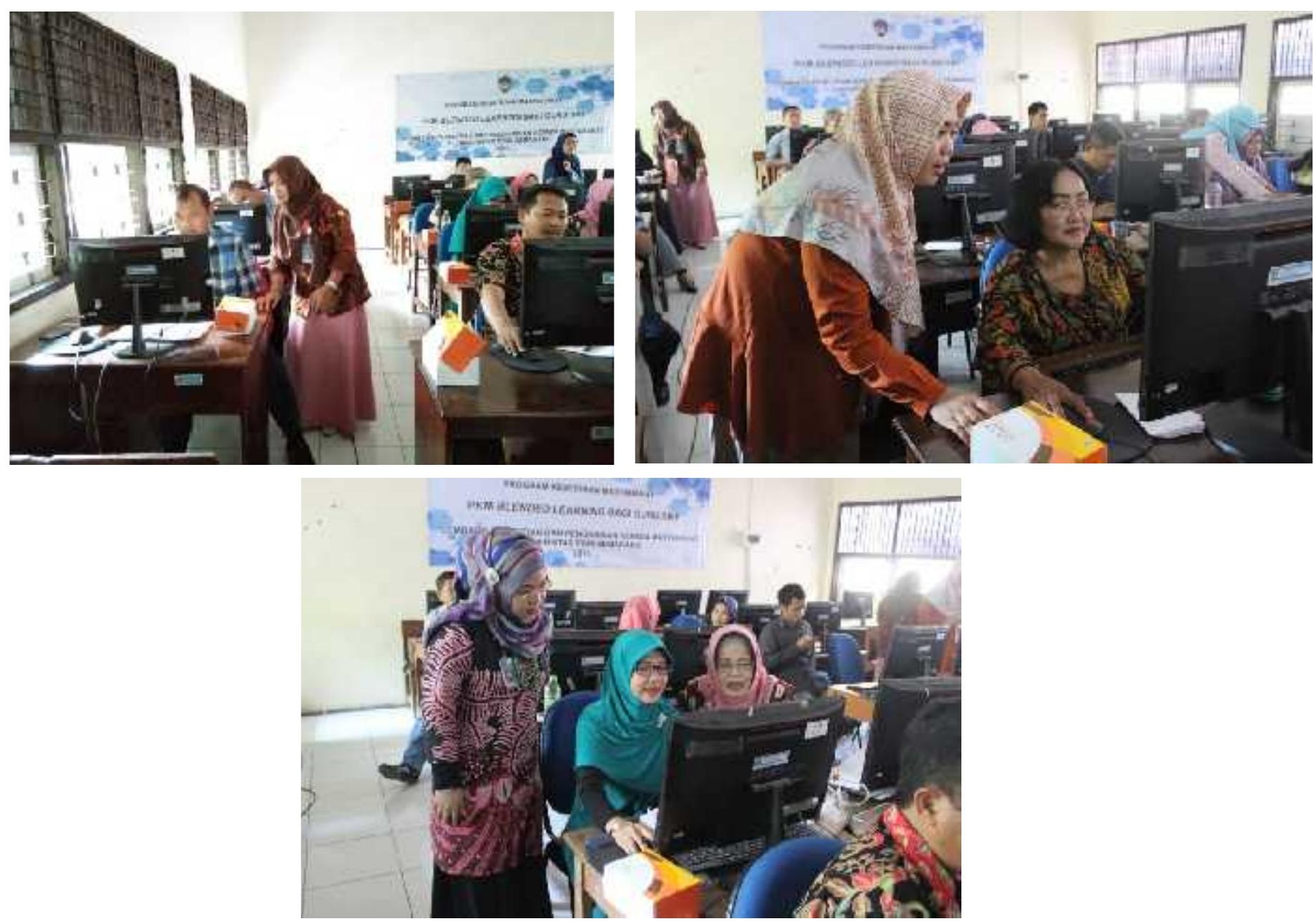

Gambar 3. Pendampingan Individu

Adapun hasil evaluasi pelaksanaan kegiatan pengabdian kepada masyarakat dan hasil respon dari peserta kegiatan adalah sebagai berikut: (1) kehadiran dan tingkat partisipasi peserta sangat baik dan terlihat pada respon para guru yang mengerjakan serta mengumpulkan penugasan kepada tim pengabdian; (2) pelaksanaan kegiatan dilaksanakan pada waktu yang tepat bagi guru karena dapat langsung dimanfaatkan untuk evaluasi akhir semester secara online; (3) di akhir kegiatan peserta workshop mendapatkan pengetahuan dan wawasan baru mengenai penggunaan media interaktif berbasis online seperti google form dan google classroom yang dapat dikombinasikan dengan pembelajaran langsung dalam bentuk Blended Learning. 


\section{SIMPULAN}

Berdasarkan pelaksanaan program kemitraan masyarakat di SMP Negeri 34 Semarang dapat disimpulkan beberapa hal sebagai berikut:

1. Para guru menghasilkan akun tiap guru matapelajaran dalam membuat google form dan google classroom.

2. Para guru mengenal blended learning dan variasi pembelajaran langsung dengan kombinasi media berbasis teknologi online berupa google form dan google classroom.

3. Keterampilan guru dalam penggunaan media pembelajaran menjadi lebih variatif karena mengoptimalisasikan penggunaan teknologi online.

4. Guru lebih optimal secara teknis dalam mempublikasikan bahan ajar dan media pembelajaran menggunakan teknologi.

Adapun saran yang direkomendasikan adalah penerapan media pembelajaran blended learning untuk mengetahui keefektifan dalam pembelajaran di sekolah.

\section{UCAPAN TERIMA KASIH}

Ucapan terima kasih ditujukan kepada Lembaga Penelitian dan Pengabdian pada Masyarakat (LPPM) Universitas PGRI Semarang sebagai pemberi dana program kemitraan masyarakat tahun anggaran 2019 serta SMP Negeri 34 Semarang sebagai mitra pengabdian masyarakat.

\section{DAFTAR PUSTAKA}

Ahrens, Zascerinska, and Andreeva. "Engineering Students' Blended Learning in Higher Education”. (2013). Web. Februari 2020.

Bishop, J. "Incentives for learning: Why American high school students compare so poorly to their counterparts overseas". (1989). Ithaca, NY: Cornell University, Center for Advanced Human Resource Studies. Web. Desember 2019.

Grgurovic, Maja. "Blended Learning in an ESL Class: A Case Study" (2011). CALICO Journal, 29(1), Sep 2011, 100-117. Web. Februari 2020.

Permen. "Peraturan Menteri Pendidikan Nasional Nomor 18 Tahun 2007 tentang Sertifikasi Guru dalam Jabatan”. Dokumen Mendiknas (2007). Web. Oktober 2019.

PP. "Peraturan Pemerintah RI Nomor 74 Tahun 2008 tentang Guru". Dokumen Peraturan Pemerintah (2008). Web. Oktober 2019.

Qiu Ming, Chen, Lin. "A Problem-based Learning Approach to Teaching an Advanced Software Engineering Course". (2011). Proc. 2nd International Workshop on Education Technology and Computer Science, 252-255. Web. Februari 2020. 
Tucker, Catlin. "Blended Learning in Grades 4-12: Leveraging the Power of Technology to Create Student Centered Classrooms”. (2012). Corwin. Web. Februari 2020. 